\title{
Neurological manifestations in COVID-19 and its possible mechanism
}

\author{
Xiaojia Tang ${ }^{1,2,}{ }^{*}$, Yuhan Luo ${ }^{1,2, *}$, Yuxia Song1,2,*, Hongyang Fan², Sisi Dong ${ }^{3}$, Peipei Liu², Yingzhu \\ Chen $^{2}$ \\ ${ }^{1}$ Department of Neurology, Dalian Medical University, Dalian 116000, Liaoning, China \\ ${ }^{2}$ Department of Neurology, Clinical Medical College, Yangzhou University, Yangzhou 225001, Jiangsu, China \\ ${ }^{3}$ The Second Xiangya Hospital, Central South University, Changsha 410000, Hunan Province, China \\ *Equal contribution
}

Correspondence to: Yingzhu Chen, Peipei Liu; email: yzchendr@163.com, https://orcid.org/0000-0002-2110-236X;

doclpp87@163.com, https://orcid.org/0000-0001-8773-7547

Keywords: COVID-19, SARS-CoV-2, polyneuropathy, rhabdomyolysis, cerebrovascular disease

Received: March 22, 2020

Accepted: July 7, 2020

Published: September 27, 2020

Copyright: (C) 2020 Tang et al. This is an open access article distributed under the terms of the Creative Commons Attribution License (CC BY 3.0), which permits unrestricted use, distribution, and reproduction in any medium, provided the original author and source are credited.

\section{ABSTRACT}

In December 2019, the first cases of the acute respiratory illness now known as Corona Virus Disease 2019 (COVID-19) occurred in Wuhan, Hubei Province, China. The main clinical manifestations of COVID-19 are a fever, dry cough and general weakness, although in some patients, a headache, tight chest, diarrhea, etc. are the first clinical manifestations. Neurological practice is involved in all aspects of medicine, from primary care for patients with migraines to consultations with patients in the intensive care unit. Few disorders spare the nervous system, and newly emerging infections are no exception. As neurologists, we are concerned about the effects of SARSCoV-2 infections on the nervous system. Multiple neuropathy, rhabdomyolysis, cerebrovascular disease, central nervous system infections and other common neurological diseases require attention during this outbreak.

\section{INTRODUCTION}

In December 2019, a number of unexplained cases of pneumonia occurred in Wuhan, China, and rapidly spread to other parts of China, then to Europe, North America, Asia and most of the world. This outbreak was confirmed to be caused by a novel coronavirus - severe acute respiratory syndrome coronavirus 2 (SARS-CoV-2) [1, 2]. On March 11, 2020, the World Health Organization declared Corona Virus Disease 2019 (COVID-19) as a pandemic [3]. As of May 7, 2020, there were 3,672,238 confirmed cases of COVID-19 and 254,045 deaths due to the disease globally [4]. The most common symptoms in patients diagnosed with SARS-CoV-2 infections are a fever and dry cough $[5,6]$. Infections caused by SARSCoV-2 exhibit many clinical similarities to those caused by SARS-CoV, such as a fever, dry cough and diarrhea during the prodromal phase [7-9].

In addition to the typical respiratory symptoms, some SARS patients have had neurological problems $[10,11]$.
Similarly, in some patients diagnosed with COVID-19, headaches, muscle aches, confusion and seizures have been the first clinical manifestations $[12,13]$. In COVID19 epidemic areas, people who have had close contact with diagnosed COVID-19 patients should be alert to the possibility of SARS-CoV-2 infection if they develop neurological symptoms such as headaches, slurred speech, hemiplegia and disturbances of consciousness. This article reviews the epidemiology of SARS-CoV-2 infections, the neurological diseases related to SARS$\mathrm{CoV}-2$, and the possible mechanisms behind these relationships.

\section{SARS-CoV-2}

SARS-CoV-2, originally named 2019-nCoV, belongs to the broader family of coronaviruses [1,2]. Coronaviruses are enveloped, positive-stranded RNA viruses that belong to the family Coronaviridae and the order Nidovirales. Six coronavirus species are known to cause respiratory, enteric, hepatic and neurologic diseases. Four of these 
viruses are prevalent - 229E, OC43, NL63 and HKU1 and typically cause common cold symptoms in immunocompetent individuals [14]. The two other strains SARS-CoV [15] and Middle East respiratory syndrome coronavirus (MERS-CoV) [16] - are zoonotic in origin, and have been linked to sometimes fatal illness. SARSCoV-2 is the seventh member of the coronavirus family. Zhou et al. found that SARS-CoV-2 was 96\% identical at the whole-genome level to a bat coronavirus, so SARS$\mathrm{CoV}-2$ may have originated in bats [17].

An epidemic or outbreak can occur when the agent (pathogen), population (hosts) and environment create an ideal situation for spread [18]. The current evidence suggests that SARS-CoV-2 may have spread to humans via wild animals sold illegally in the Huanan Seafood Wholesale Market [19]. The extent of humanto-human transmission of SARS-CoV-2 was unclear at first, but now there is evidence of human-to-human transmission [5, 20,21]. The main sources of infection are SARS-CoV-2-infected patients, including those who are asymptomatic [22]. The routes of transmission include droplet transmission, contact transmission and aerosol transmission $[23,24]$. In a recent study, SARSCoV-2 was detected in stool samples from patients with abdominal symptoms [20, 25], so some scholars have proposed that SARS-CoV-2 could spread via fecal-oral transmission. Further environmental studies will be needed to determine whether the virus remains viable under conditions that would favor fecal-oral transmission [26]. SARS-CoV-2 has not been confirmed to be transmitted vertically from mother to child [27]. Based on the available data, a Chinese team estimated a basic reproduction number (R0) of 3.77 for SARS-CoV-2, basically confirming that the new coronavirus is more contagious than SARS [28].

SARS-CoV-2 employs a densely glycosylated, homotrimeric class I fusion spike (S) protein to enter host cells. The $\mathrm{S}$ protein exists in a metastable prefusion conformation that undergoes a dramatic structural rearrangement to fuse the viral membrane with the host cell membrane [29, 30]. Epidemiological data indicate that the population is generally susceptible to SARS-CoV-2 [31]. Therefore, it is necessary for individuals to wash or disinfect their hands frequently, go outside less, wear a mask, avoid group activities, stay away from patients with COVID-19, maintain good living habits and keep an optimistic attitude [32-34].

\section{Neurological disease}

SARS-CoV-2 has been reported to be associated with Guillain-Barré syndrome, rhabdomyolysis, acute cerebrovascular disease, central nervous system infections and other neurological diseases. Four formal reports have described neurological problems in SARS patients, including polyneuropathy [35], myopathy and rhabdomyolysis [36], large artery ischemic stroke [37] and central nervous system infections [38]. Human coronaviruses (HCoVs) can naturally reach the central nervous system, and could potentially cause neurological symptoms. Among the coronavirus-induced animal diseases, feline infectious peritonitis virus, mouse hepatitis virus and hemagglutinating encephalomyelitis virus can all reach the central nervous system and induce different types of neuropathologies [10, 11]. The structure of SARS-CoV-2 is similar to that of the SARS virus, and both viruses invade the human body through the angiotensin converting enzyme II (ACE2) receptor. Thus, in this paper, we mainly describe the neurological diseases associated with SARS-CoV-2, but also briefly introduce the neurological diseases associated with SARS.

\section{Neuromuscular manifestations}

\section{Polyneuropathy}

Polyneuropathy, also known as peripheral neuropathy, is multiple-nerve damage of the extremities. The clinical manifestations are mostly distal symmetrical motor sensory dysfunction and autonomic nerve dysfunction [39]. The causes of polyneuropathic disorders include metabolic, toxic, infectious, inflammatory, autoimmune and genetic conditions [40]. Zhao et al. reported a case of COVID-19 initially presenting with acute GuillainBarré syndrome (GBS). The female patient aged 61 years presented with acute weakness in both legs and severe fatigue. She received intravenous immunoglobulin, antiviral drugs of arbidol, lopinavir, and ritonavir, and supportive care. After 30 days of treatment, the muscle strength of the limbs returned to normal and the respiratory symptoms disappeared [41]. In a recently published article, two COVID-19 patients were diagnosed with Miller-Fisher syndrome (MFS) and multiple cranial neuritis, respectively [42]. These cases suggest a possible link between GBS and SARS-CoV-2 infection.

Some patients with severe COVID-19 progress rapidly and need to be transferred to an intensive care unit (ICU) for further treatment [43, 44]. In such patients, the peripheral nerves could be particularly susceptible to peripheral microcirculation disturbances, since the vessels supplying them with blood lack autoregulation [45]. ICU-acquired weakness, which can manifest as critical-illness polyneuropathy, critical-illness myopathy or both, is a frequent and disabling disorder in ICU patients [46]. Critical-illness polyneuropathy, an axonal sensory-motor polyneuropathy, is observed in up to a third of critically ill patients with systemic inflammatory response syndrome. Critical-illness myopathy, an acute 
myopathy, develops in a similar setting, often in association with the use of corticosteroids and/or nondepolarizing neuromuscular-blocking agents [47].

Tsai et al. [35] presented data from four patients with probable SARS who developed axonal polyneuropathy, myopathy or both (2004). All of them had received intubation for respiratory distress and a high dose of steroid therapy for multiple organ failure. They developed distal-predominant weakness in all four limbs and a mild decrease in deep-tendon reflexes three to four weeks after the onset of SARS. The most likely diagnoses were critical-illness polyneuropathy and/or critical-illness myopathy. Some viruses, such as cytomegalovirus and varicella zoster virus, may cause peripheral neuropathy by directly attacking the nerves. It is not known whether direct attacks of the peripheral nervous system occur in $\mathrm{HCoV}$-associated neuropathy.

\section{Rhabdomyolysis}

Rhabdomyolysis refers to the damage to striated muscle, the destruction of the muscle cell membrane integrity and the release of myoglobin, creatine kinase, other enzymes, small molecules and toxic substances into the systemic circulation due to various traumatic and non-traumatic factors, resulting in a group of clinical syndromes of organ damage [48, 49]. Clinical examination, history evaluation, laboratory studies, muscle biopsies and genetic testing are useful tools for diagnosing rhabdomyolysis and differentiating acquired from inherited cases. Acquired cases may be due to substance abuse, medication or toxic exposures, electrolyte abnormalities, endocrine disturbances and autoimmune myopathies [50].

In several recent studies on COVID-19 [5, 12, 20], a few patients exhibited varying degrees of myalgia, fatigue and elevated creatine and creatine kinase levels. In the study of Guan et al., two patients clearly developed rhabdomyolysis as a complication of COVID-19, while $14.90 \%$ (164/1099) exhibited myalgia or arthralgia symptoms and $13.7 \%$ (90/657) had creatine kinase levels $\geq 200$ U/L [5]. Tong's research group reported that a patient diagnosed with COVID-19 had pain and weakness in both lower limbs and obvious tenderness after the ninth day of admission. Laboratory examination indicated that the patient's myoglobin level was $>12,000.0 \mu \mathrm{g} / \mathrm{L}$ (reference $0-140$ $\mu \mathrm{g} / \mathrm{L}$ ), creatine kinase was $11,842 \mathrm{U} / \mathrm{L}$ (reference 38 $174 \mathrm{U} / \mathrm{L}$ ) and lactate dehydrogenase was 2,347 U/L (reference 109-245 U/L). The authors added hydration, alkalization, plasma transfusion, gamma globulin and symptomatic support therapy based on the patient's previous treatment with oxygen, antivirals, antibiotics and methylprednisolone [51]. Creatine kinase and myoglobin are important indicators of rhabdomyolysis, but they are not routinely detected in the clinical practice. When patients have local muscle pain and weakness, rhabdomyolysis should be considered.

In previous SARS studies, some patients were clearly diagnosed with critical-illness myopathy [35] and rhabdomyolysis $[50,52]$. In such patients, it cannot be ruled out that rhabdomyolysis may have developed due to the use of corticosteroids and/or nondepolarizing neuromuscular-blocking agents; however, the association of rhabdomyolysis with viruses such as influenza viruses $\mathrm{A}$ and $\mathrm{B}$, human immunodeficiency virus, Coxsackie virus, cytomegalovirus, West Nile virus and dengue virus has also been well described [53-56]. Nevertheless, there is not yet sufficient evidence that $\mathrm{HCoVs}$ can directly invade muscle cells.

\section{Acute cerebrovascular disease}

The population is generally susceptible to SARS-CoV2 , but the elderly are more susceptible (the median age of hospitalized patients in one study was 56 years [interquartile range, 42-68 years; range, 22-92 years] [20]), and such patients are already at high risk for cerebrovascular diseases. Viral infections are known to be associated with an increased risk of stroke [57]. In a study by Mao et al., 214 patients diagnosed with COVID-19 were enrolled, and six (2.80\%) of them developed acute cerebrovascular disease (five cases of ischemic stroke and one case of cerebral hemorrhage). All but one of these patients (an ischemic stroke patient) died of respiratory failure [13]. In a study of 206 SARS patients in Singapore, large artery stroke was diagnosed in five patients, of whom four were critically ill and three died [58]. Strokes are not uncommon in critically ill patients with multiple comorbidities, so SARS-CoV2 infections in humans may increase the risk of stroke.

\section{Central nervous system infection}

Central nervous system infections are among the most critical problems in public health, as patients frequently exhibit neurologic sequelae. The clinical manifestations include a fever, headache, vomiting, stiff neck, afebrile seizures and status epilepticus. $\mathrm{HCoVs}$ cause a certain degree of nerve erosion, but their capacity to infect the central nervous system in humans has not been well characterized [10, 59]. Moriguchi et al. described a patient with SARS-CoV-2-associated meningitis who was brought to the hospital by ambulance due to convulsions and a coma. Interestingly, SARS-CoV-2 RNA was not detected in the patient's nasopharyngeal swab, but was detected in the patient's cerebrospinal fluid [60]. Zhao et al. [61] reported spinal cord involvement in a COVID-19 patient one week after the onset of fever. After admission, his SARS-CoV-2 RNA 
nasopharyngeal swab test was positive. Based on the patient's acute flaccid myelitis of the lower limbs, urinary and bowel incontinence, and sensory level at T10, a diagnosis of acute myelitis was more likely. After the patient had been treated with high-flow oxygen, antiviral medication, steroids and human immunoglobulin, his body temperature returned to normal and two subsequent SARS-CoV-2 RNA nasopharyngeal swab tests were negative. The muscle strength of both upper limbs recovered to grade $4 / 5$, while the muscle strength of both lower limbs was grade $1 / 5$. This study indicated that acute myelitis may be a neurological complication of COVID-19. The above cases demonstrate the potential for neurological invasion of SARS-CoV-2.

The presence of $\mathrm{HCoV}$ in human central nervous system-related samples was detected as early as 1980 in autopsies of patients with multiple sclerosis [62]. In 2004, genetic material from SARS-CoV was detected in cerebrospinal fluid samples from a 32-year-old woman. The patient had a generalized tonic-clonic convulsions with loss of consciousness and up-rolling eyeballs lasting for one minute [38]. Another patient, a doctor infected with the SARS virus, had symptoms of restlessness, vomiting and confusion on the 33th day of illness. The patient died after treatment failed, and a brain biopsy was performed. A fragment specific for SARS HCoV was amplified from cultures of the brain suspension, and transmission electronic microscopy revealed the presence of an enveloped virus morphologically compatible with a coronavirus in the cultures [63]. Since some COVID-19 patients have complained of headaches, nausea etc, care providers should be alert for central nervous system infections caused by SARS-CoV-2 if such patients also exhibit symptoms such as a fever, epilepsy and disturbances of consciousness.

\section{Mechanisms of nervous system damage due to SARS-CoV-2 infections}

In this section, we will explore various mechanisms that may explain the correlation between COVID-19 and neurological disease.

\section{Hypoxemia}

In a clinical retrospective study of 138 people, the most common complication of COVID-19 during hospital admission was pneumonia, followed by acute respiratory distress syndrome (19.60\%) and shock (8.70\%) [20]. The patients in this study had varying degrees of hypoxia, accompanied by hypoxemia. Most patients received oxygen inhalation (ordinary oxygen inhalation, $106[76.81 \%])$, and many received mechanical ventilation (non-invasive ventilation, 15 [10.09\%]; intermittent mandatory ventilation, 17 [12.32\%]). More than $20 \%$ of the oxygen consumed by humans is used by the brain for ATP production to generate the required membrane potential [64]. As soon as anoxia sets in, ATP synthase begins to pump protons out of the mitochondrial matrix to maintain the mitochondrial membrane potential. Continued lack of oxygen can eventually lead to the loss of high-energy phosphate esters, disturbances of neurotransmitter metabolism, the breakdown of the membrane, the failure of mitochondria and the accumulation of intracellular $\mathrm{Ca}^{2+}$. The immediate consequence is irreversible neurological damage and even neuronal death $[64,65]$.

Lack of oxygen increases the risk of stroke. For instance, the prolonged hypoxia of obstructive sleep apnea hypopnea syndrome can damage the sleep structure, increase blood pressure, reduce cerebral blood flow and promote microthrombosis and atherosclerosis, thus impacting the prognosis and recurrence of cerebral infarction $[66,67]$. Mao et al. reported that six COVID19 patients had acute cerebrovascular disease: five with severe infections $(5 / 88)$ and one with a non-severe infection (1/126) $(\mathrm{P}=0.03)$ [13]. The symptoms of hypoxia in COVID-19 patients are very obvious, and critical patients need ventilator support. COVID-19 patients admitted to the ICU tend to be older and have a greater number of comorbid conditions (e.g., hypertension, diabetes, cardiovascular and cerebrovascular diseases) than those not admitted to the ICU [20]. This suggests that older age and these comorbidities may be risk factors for poor outcomes $[68,69]$.

\section{ACE2}

The metallopeptidase ACE2 has been confirmed to be the cell receptor for SARS-CoV-2, just as it is for SARS-CoV [70, 71]. However, SARS-CoV-2 cannot enter cells through other coronavirus receptors such as aminopeptidase $\mathrm{N}$ and dipeptidyl peptidase [71]. ACE2 is highly expressed not only in the alveolar type II cells of the lungs and the upper and stratified epithelial cells of the esophagus, but also in the absorptive enterocytes of the ileum and colon [72, 73]. The main physiological function of ACE2 is to catalyze the conversion of angiotensin II to angiotensin (1-7), with a vasodilator effect. In brain tissues, angiotensin (1-7) stimulates Mas receptors to promote angiogenesis, and also inhibits oxidative stress, prevents neuroinflammation, improves cerebral blood flow, suppresses apoptosis and protects cerebral blood vessels [74].

Enhancing the expression of ACE2 may be an important strategy for treating cardiovascular and cerebrovascular 
diseases [75]. SARS-CoV-2 patients with cerebrovascular disease may be more likely to develop into severe patients with a higher risk of death, so more timely diagnosis is needed for such patients. ACEI and angiotensin II receptor blocker antihypertensive drugs may increase the expression of the ACE2 receptor [76]. In order to avoid aggravating SARS-CoV-2 infection symptoms, it is recommended that hypertensive patients on blood pressure control medications stop using ACEI and angiotensin II receptor blocker antihypertensive drugs, and instead use calcium channel blocker diuretic antihypertensive drugs [77].

\section{Immunization}

The responses of the immune system can be divided into innate immunity (also known as non-specific immunity) and adaptive immunity (also known as specific immunity, which can be further divided into humoral immunity and cellular immunity) [76, 78]. The immune mechanisms induced by SARS-CoV-2 are unclear. After SARS-CoV-2 enters the body through ACE2, host factors trigger an immune response against the virus. The virus induces natural immunity, phagocytosis and phagocytic cell death, thus damaging tissues and organs. In four clinical retrospective studies that clearly identified the diagnosis of COVID-19 [12, $19,20,79]$, the absolute value of lymphocytes in most patients was reduced. These findings suggest that SARS-CoV-2 mainly attacks lymphocytes, especially T lymphocytes, similar to SARS-CoV.

CD4+ T cells are well known to regulate or "assist" the functioning of other lymphocytes. CD8+ T cells are cytotoxic and can kill virus-infected cells [80]. Barton et al. [81] reported that in two autopsies of COVID-19 patients, immunohistochemistry revealed a small number of CD3+ T lymphocytes infiltrating the alveolar septum, while CD20+ B-lymphocytes were rare. CD8+ $\mathrm{T}$ cells were slightly more prevalent than CD4+ T cells, and CD68 detection revealed a few macrophages. Some studies have suggested that the substantial decrease in the total number of lymphocytes in coronavirus patients may indicate that the virus consumes many immune cells and inhibits cellular immune function $[82,83]$.

After an antigen enters the body, the corresponding antigen-specific B cells are activated, induced to proliferate and eventually stimulated to differentiate into plasma cells. These plasma cells then produce specific antibodies that can enter the body fluid and exert immune effects. It is widely accepted that immunoglobulin $M(\operatorname{IgM})$ provides the first line of defense during viral infections, prior to the generation of adaptive, high-affinity $\operatorname{IgG}$ responses that are important for long-term immunity and immunological memory [84]. Li et al. successfully developed a rapid detection IgG-IgM combined antibody test kit for the diagnosis of COVID-19. The kit has a sensitivity of $88.66 \%$ and a specificity of $90.63 \%$, and can detect the infection within 15 minutes [85]. After the rehabilitation of most patients with the novel coronavirus, the body will produce specific antibodies that can kill and eliminate the virus.

On February 8, 2020, with the Pneumonia Diagnosis and Treatment Program for Novel Coronavirus Infection (Trial Version 5) [86] as a guide, The First People's Hospital of Jiangxia District carried out the first phase of a new convalescent plasma treatment on three critically ill patients. After 12 to 24 hours of convalescent plasma therapy, the patients' laboratory examination results, clinical signs and symptoms improved significantly. Plasma therapy not only is safe and potentially effective, but also stimulates humoral immunity [87].

Most COVID-19 patients have a good prognosis, while a few patients have mild symptoms in the early stage and suddenly deteriorate in the later stage of the disease or during the recovery process. A large number of patients have exhibited a 'cytokine storm' (the rapid production of cytokines such as tumor necrosis factor alpha, interleukin-1, interleukin-6 and interferon gamma) due to the viral infection, which sometimes has progressed to acute respiratory distress syndrome and multiple organ failure [12, 19]. It is already known that $\mathrm{HCoV}$ can spread from the respiratory tract to the central nervous system through transneuronal and hematogenous routes, resulting in encephalitis and neurological diseases [88]. The invasion of the blood-brain barrier by the coronavirus can destroy vascular endothelial connections, leading to blood-brain barrier dysfunction and enhanced permeability [89]. When the virus invades the human brain, it triggers immune damage, causing brain damage and acute or chronic inflammation, thus creating a vicious cycle.

\section{Inflammation}

Several current retrospective clinical studies have described COVID-19 patients with abnormally low lymphocyte counts, Prolonged prothrombin times and significantly increased lactate dehydrogenase levels. Patients transferred to the ICU had significantly higher white blood cell and neutrophil counts than those not transferred to the ICU, as well as higher levels of D-dimer, creatine kinase and creatine [20]. The complications in severe cases have included rhabdomyolysis, shock, acute cardiac injury and acute kidney injury. Several mechanisms are thought to link 
infections with acute vascular events, including the release of proinflammatory cytokines, the disruption of atherosclerotic plaques, physiological changes in the heart rate and vasoconstriction [90]. The inflammatory response in severe pneumonia is not limited to lung tissue; rather, the systemic inflammatory response is activated, and its amplification cascade impairs the function of distant organs [57, 91].

\section{Hypercoagulability}

Middle-aged and elderly patients account for the majority of COVID-19 patients (especially critically ill patients) with abnormally increased D-dimer levels, and such patients are more prone to embolic vascular events and cerebrovascular disease [20]. Umapathi et al. postulated that a hypercoagulable state predisposed a group of mainly critically ill SARS patients to large cerebral arterial thromboembolism [58]. Providers treating critically ill COVID-19 patients with underlying diseases such as hypertension, diabetes, cancer, etc. should be alert to the potential for hypercoagulability and regularly assess routine blood coagulation.

\section{Ethics statement}

Our research does not require an ethics statement.

\section{CONCLUSIONS}

SARS-CoV-2 infection may involve the nervous system, and may cause diseases such as polyneuropathy, myopathy, cerebral infarction and central nervous system infections. Cerebral infarction is the second most common cause of death and the leading cause of adult disability worldwide. Patients with cerebrovascular diseases may face greater risks during infections, so it is necessary to strengthen protection to avoid infection, perform secondary prevention measures and monitor patients' symptoms and vital signs. During the period of high incidence of COVID-19, neurologists need to pay great attention to the treatment of patients, especially those whose first symptoms are neurological symptoms.

\section{AUTHOR CONTRIBUTIONS}

Xiaojia Tang, Peipei Liu and Yingzhu Chen conceived and designed the research. Xiaojia Tan wrote the manuscript, and all authors contributed to manuscript revision, read and approved the submitted version.

\section{ACKNOWLEDGMENTS}

The authors thank Professor Yingzhu Chen and Peipei Liu, M.D., Ph.D.

\section{CONFLICTS OF INTEREST}

No potential conflicts of interest were reported by the authors.

\section{FUNDING}

This work was supported by the "Six Talent Peaks" project of Jiangsu Province (No. WSW-246), "333 Project" science program of Jiangsu Province (No. BRA2015187) and the "Thirteenth Five-Year" Special Fund for Science, Education and Health of Yangzhou (NO. LJRC20187).

\section{REFERENCES}

1. Zhu N, Zhang D, Wang W, Li X, Yang B, Song J, Zhao X, Huang B, Shi W, Lu R, Niu P, Zhan F, Ma X, et al, and China Novel Coronavirus Investigating and Research Team. A novel coronavirus from patients with pneumonia in China, 2019. N Engl J Med. 2020; 382:727-33.

https://doi.org/10.1056/NEJMoa2001017 PMID:31978945

2. Coronaviridae Study Group of the International Committee on Taxonomy of Viruses. The species severe acute respiratory syndrome-related coronavirus: classifying 2019-nCoV and naming it SARSCoV-2. Nat Microbiol. 2020; 5:536-44. https://doi.org/10.1038/s41564-020-0695-z PMID:32123347

3. WHO Director-General's opening remarks at the media briefing on COVID-19 - March 11, 2020. https://www.who.int/dg/speeches/detail/whodirector-general-s-opening-remarks-at-the-mediabriefing-on-covid-19---11-march-2020.

4. https://www.who.int/docs/default-source/ coronaviruse/situation-reports/20200507covid-19sitrep-108.pdf?sfvrsn=44cc8ed8 2.

5. Guan WJ, Ni ZY, Hu Y, Liang WH, Ou CQ, He JX, Liu L, Shan H, Lei CL, Hui DSC, Du B, Li LJ, Zeng G, et al., and China Medical Treatment Expert Group for Covid-19. Clinical Characteristics of Coronavirus Disease 2019 in China. N Engl J Med. 2020; 382:1708-1720.

https://doi.org/10.1056/NEJMoa2002032

PMID:32109013

6. Sun P, Qie S, Liu Z, Ren J, Li K, Xi J. Clinical characteristics of 50466 hospitalized patients with 2019-nCoV infection. J MED VIROL. 2020. https://doi.org/10.2139/ssrn.3539664

7. Nanshan Z. SARS diagnosis and treatment protocol. Natl Med J China. 2003; 83. 
8. Lei C, Fuchun Z. Clinical analysis of 260 cases of SARS in GuangZhou. J Infect Dis. 2003; 21.

9. Zhong N. Management and prevention of SARS in China. Philos Trans R Soc Lond B Biol Sci. 2004; 359:1115-16.

https://doi.org/10.1098/rstb.2004.1491

PMID:15306397

10. Desforges $M$, Le Coupanec A, Dubeau P, Bourgouin A, Lajoie L, Dubé M, Talbot PJ. Human coronaviruses and other respiratory viruses: underestimated opportunistic pathogens of the central nervous system? Viruses. 2019; 12:14.

https://doi.org/10.3390/v12010014

PMID:31861926

11. Tsai LK, Hsieh ST, Chang YC. Neurological manifestations in severe acute respiratory syndrome. Acta Neurol Taiwan. 2005; 14:113-19.

PMID:16252612

12. Chen N, Zhou M, Dong X, Qu J, Gong F, Han Y, Qiu Y, Wang J, Liu Y, Wei Y, Xia J, Yu T, Zhang X, Zhang L. Epidemiological and clinical characteristics of 99 cases of 2019 novel coronavirus pneumonia in Wuhan, China: a descriptive study. Lancet. 2020; 395:507-13.

https://doi.org/10.1016/S0140-6736(20)30211-7 PMID:32007143

13. Mao L, Jin $H$, Wang $M, H u Y$, Chen $S$, He $Q$, Chang J, Hong C, Zhou Y, Wang D, Miao X, Li Y, Hu B. Neurologic manifestations of hospitalized patients with coronavirus disease 2019 in Wuhan, China. JAMA Neurol. 2020; 77:1-9.

https://doi.org/10.1001/jamaneurol.2020.1127 PMID:32275288

14. Corman VM, Lienau J, Witzenrath M. [Coronaviruses as the cause of respiratory infections]. Internist (Berl). 2019; 60:1136-45.

https://doi.org/10.1007/s00108-019-00671-5 PMID:31455974

15. Luk HK, Li X, Fung J, Lau SK, Woo PC. Molecular epidemiology, evolution and phylogeny of SARS coronavirus. Infect Genet Evol. 2019; 71:21-30.

https://doi.org/10.1016/j.meegid.2019.03.001 PMID:30844511

16. Nassar MS, Bakhrebah MA, Meo SA, Alsuabeyl MS, Zaher WA. Middle East Respiratory Syndrome Coronavirus (MERS-CoV) infection: epidemiology, pathogenesis and clinical characteristics. Eur Rev Med Pharmacol Sci. 2018; 22:4956-4961.

https://doi.org/10.26355/eurrev 201808 15635 PMID:30070331

17. Zhou $P$, Yang $X L$, Wang $X G$, Hu B, Zhang L, Zhang W, Si HR, Zhu Y, Li B, Huang CL, Chen HD, Chen J, Luo Y, et al.
A pneumonia outbreak associated with a new coronavirus of probable bat origin. Nature. 2020; 579:270-73.

https://doi.org/10.1038/s41586-020-2012-7 PMID:32015507

18. Ameli J. Communicable diseases and outbreak control. Turk J Emerg Med. 2016 (Suppl 1); 15:20-26. https://doi.org/10.5505/1304.7361.2015.19970 PMID:27437528

19. Huang C, Wang Y, Li X, Ren L, Zhao J, Hu Y, Zhang L, Fan G, Xu J, Gu X, Cheng Z, Yu T, Xia J, et al. Clinical features of patients infected with 2019 novel coronavirus in Wuhan, China. Lancet. 2020; 395:497-506. https://doi.org/10.1016/S0140-6736(20)30183-5 PMID:31986264

20. Wang D, Hu B, Hu C, Zhu F, Liu X, Zhang J, Wang B, Xiang $\mathrm{H}$, Cheng $Z$, Xiong $\mathrm{Y}$, Zhao $\mathrm{Y}$, Li $\mathrm{Y}$, Wang $\mathrm{X}$, Peng $\mathrm{Z}$. Clinical characteristics of 138 hospitalized patients with 2019 novel coronavirus-infected pneumonia in Wuhan, China. JAMA. 2020; 323:1061-69. https://doi.org/10.1001/jama.2020.1585 PMID:32031570

21. Riou J, Althaus CL. Pattern of early human-to-human transmission of Wuhan 2019 novel coronavirus (2019nCoV), December 2019 to January 2020. Euro Surveill. 2020; 25:2000058. https://doi.org/10.2807/15607917.ES.2020.25.4.2000058 PMID: $\underline{32019669}$

22. National Health Commission of the People's Republic of China. Diagnosis and treatment of the novel coronavirus pneumonia (Trial version 7) [D]. http://www.nhc.gov.cn/yzygj/s7653p/202003/46c929 4a7dfe4cef80dc7f5912eb1989/files/ce3e6945832a438 eaae415350a8ce964.pdf. 2020.

23. Fathizadeh $H$, Maroufi $P$, Momen-Heravi $M$, Dao $S$, Köse Ş, Ganbarov K, Pagliano P, Esposito S, Kafil HS. Protection and disinfection policies against SARS-CoV-2 (COVID-19). Infez Med. 2020; 28:185-91. PMID: $\underline{32275260}$

24. Yang C, Ma QY, Zheng YH, Yang YX. [Transmission routes of 2019-novel coronavirus (2019-nCoV)]. Zhonghua Yu Fang Yi Xue Za Zhi. 2020; 54:374-77. https://doi.org/10.3760/cma.j.cn112150-202002160016 PMID:32268644

25. Li LY, Wu W, Chen S, Gu JW, Li XL, Song HJ, Du F, Wang G, Zhong CQ, Wang XY, Chen Y, Shah R, Yang $\mathrm{HM}$, Cai $\mathrm{Q}$. Digestive system involvement of novel coronavirus infection: prevention and control infection from a gastroenterology perspective. J Dig Dis. 2020; 21:199-204. https://doi.org/10.1111/1751-2980.12862 PMID:32267098 
26. Yeo C, Kaushal S, Yeo D. Enteric involvement of coronaviruses: is faecal-oral transmission of SARS-CoV2 possible? Lancet Gastroenterol Hepatol. 2020; 5:335-37.

https://doi.org/10.1016/S2468-1253(20)30048-0

PMID:32087098

27. Zhu H, Wang L, Fang C, Peng S, Zhang L, Chang G, Xia S, Zhou W. Clinical analysis of 10 neonates born to mothers with 2019-nCoV pneumonia. Transl Pediatr. 2020; 9:51-60.

https://doi.org/10.21037/tp.2020.02.06

PMID: $\underline{32154135}$

28. Yang $Y$, Lu $Q$, Liu $M$, Wang $Y$, Zhang $A$, Jalali $N$, Dean $N$, Longini I, Halloran ME, Xu B, Zhang X, Wang L, Liu W, Fang L. Epidemiological and clinical features of the 2019 novel coronavirus outbreak in China. bioRxiv. https://doi.org/10.1101/2020.02.10.20021675

29. Wrapp D, Wang N, Corbett KS, Goldsmith JA, Hsieh CL, Abiona O, Graham BS, McLellan JS. cryo-EM structure of the 2019-nCoV spike in the prefusion conformation. Science. 2020; 367:1260-63.

https://doi.org/10.1126/science.abb2507 PMID:32075877

30. Xu X, Chen P, Wang J, Feng J, Zhou H, Li X, Zhong W, Hao P. Evolution of the novel coronavirus from the ongoing Wuhan outbreak and modeling of its spike protein for risk of human transmission. Sci China Life Sci. 2020; 63:457-60.

https://doi.org/10.1007/s11427-020-1637-5

PMID:32009228

31. Special Expert Group for Control of the Epidemic of Novel Coronavirus Pneumonia of the Chinese Preventive Medicine Association. [An update on the epidemiological characteristics of novel coronavirus pneumonia (COVID-19)]. Zhonghua Liu Xing Bing Xue Za Zhi. 2020; 41:139-44.

https://doi.org/10.3760/cma.j.issn.02546450.2020.02.002 PMID:32057211

32. Han G, Zhou YH. Possibly critical role of wearing masks in general population in controlling COVID-19. J Med Virol. 2020; 10:1002.

https://doi.org/10.1002/jmv.25886 PMID:32293711

33. Lin $\mathrm{YH}$, Liu $\mathrm{CH}$, Chiu YC. Google searches for the keywords of "wash hands" predict the speed of national spread of COVID-19 outbreak among 21 countries. Brain Behav Immun. 2020; 87:30-32.

https://doi.org/10.1016/j.bbi.2020.04.020

PMID:32283286

34. Ma QX, Shan H, Zhang HL, Li GM, Yang RM, Chen JM. Potential utilities of mask-wearing and instant hand hygiene for fighting SARS-CoV-2. J Med Virol. 2020; 10:1002. https://doi.org/10.1002/jmv.25805 PMID:32232986

35. Tsai LK, Hsieh ST, Chao CC, Chen YC, Lin YH, Chang SC, Chang YC. Neuromuscular disorders in severe acute respiratory syndrome. Arch Neurol. 2004; 61:1669-73. https://doi.org/10.1001/archneur.61.11.1669 PMID:15534177

36. Engel WK. Intravenous immunoglobulin $\mathrm{G}$ is remarkably beneficial in chronic immune dysschwannian/dysneuronal polyneuropathy, diabetes-2 neuropathy, and potentially in severe acute respiratory syndrome. Acta Myol. 2003; 22:97-103. PMID:15088499

37. Zochodne DW. SARS, SIRS, and neurological disease. Arch Neurol. 2004; 61:1647-48.

https://doi.org/10.1001/archneur.61.11.1647 PMID:15534173

38. Lau KK, Yu WC, Chu CM, Lau ST, Sheng B, Yuen KY. Possible central nervous system infection by SARS coronavirus. Emerg Infect Dis. 2004; 10:342-44.

https://doi.org/10.3201/eid1002.030638

PMID:15030709

39. Sommer C, Geber C, Young P, Forst R, Birklein F, Schoser B. Polyneuropathies. Dtsch Arztebl Int. 2018; 115:83-90.

https://doi.org/10.3238/arztebl.2018.083 PMID:29478436

40. Gwathmey KG, Pearson KT. Diagnosis and management of sensory polyneuropathy. BMJ. 2019; 365:I1108. https://doi.org/10.1136/bmj.I1108 PMID:31068323

41. Zhao H, Shen D, Zhou H, Liu J, Chen S. Guillain-Barré syndrome associated with SARS-CoV-2 infection: causality or coincidence? Lancet Neurol. 2020; 19:383-84.

https://doi.org/10.1016/S1474-4422(20)30109-5 PMID:32246917

42. Gutiérrez-Ortiz C, Méndez A, Rodrigo-Rey S, San PedroMurillo E, Bermejo-Guerrero L, Gordo-Mañas R, de Aragón-Gómez F, Benito-León J. Miller Fisher syndrome and polyneuritis cranialis in COVID-19. Neurology. 2020; 95:e601-05. https://doi.org/10.1212/WNL.0000000000009619 PMID: $\underline{32303650}$

43. Li T, Lu H, Zhang W. Clinical observation and management of COVID-19 patients. Emerg Microbes Infect. 2020; 9:687-90. https://doi.org/10.1080/22221751.2020.1741327 PMID:32208840

44. Jin $\mathrm{YH}$, Cai $\mathrm{L}$, Cheng ZS, Cheng $\mathrm{H}$, Deng $\mathrm{T}$, Fan $\mathrm{YP}$, Fang C, Huang D, Huang LQ, Huang Q, Han Y, Hu B, Hu F, et al, and for the Zhongnan Hospital of Wuhan University 
Novel Coronavirus Management and Research Team, Evidence-Based Medicine Chapter of China International Exchange and Promotive Association for Medical and Health Care (CPAM). A rapid advice guideline for the diagnosis and treatment of 2019 novel coronavirus (2019-nCoV) infected pneumonia (standard version). Mil Med Res. 2020; 7:4. https://doi.org/10.1186/s40779-020-0233-6 PMID:32029004

45. Witt NJ, Zochodne DW, Bolton CF, Grand'Maison F, Wells G, Young GB, Sibbald WJ. Peripheral nerve function in sepsis and multiple organ failure. Chest. 1991; 99:176-84.

https://doi.org/10.1378/chest.99.1.176 PMID:1845860

46. Intiso D. ICU-acquired weakness: should medical sovereignty belong to any specialist? Crit Care. 2018; 22:1.

https://doi.org/10.1186/s13054-017-1923-7 PMID:29301549

47. Bird SJ. Diagnosis and management of critical illness polyneuropathy and critical illness myopathy. Curr Treat Options Neurol. 2007; 9:85-92. https://doi.org/10.1007/s11940-007-0034-1 PMID:17298769

48. Nance JR, Mammen AL. Diagnostic evaluation of rhabdomyolysis. Muscle Nerve. 2015; 51:793-810.

https://doi.org/10.1002/mus.24606 PMID:25678154

49. Huerta-Alardín AL, Varon J, Marik PE. Bench-to-bedside review: rhabdomyolysis - an overview for clinicians. Crit Care. 2005; 9:158-69. https://doi.org/10.1186/cc2978 PMID:15774072

50. Chen LL, Hsu CW, Tian YC, Fang JT. Rhabdomyolysis associated with acute renal failure in patients with severe acute respiratory syndrome. Int J Clin Pract. 2005; 59:1162-66.

https://doi.org/10.1111/j.1368-5031.2005.00540.x PMID:16178983

51. Jin $\mathrm{M}$, Tong $\mathrm{Q}$. Rhabdomyolysis as potential late complication associated with COVID-19. Emerg Infect Dis. 2020; 26:1618-20. https://doi.org/10.3201/eid2607.200445 PMID: 32197060

52. Wang JL, Wang JT, Yu CJ, Chen YC, Hsueh PR, Hsiao CH, Kao CL, Chang SC, Yang PC. Rhabdomyolysis associated with probable SARS. Am J Med. 2003; 115:421-22. https://doi.org/10.1016/s0002-9343(03)00448-0 PMID: 14553890

53. Fröhlich G, Grawe A, Schmidt N, Roth R, MärkerHermann E. [Difficult course of rhabdomyolysis in influenza A/H1N1]. Dtsch Med Wochenschr. 2013; 138:2351-54. https://doi.org/10.1055/s-0033-1349642

PMID:24193860

54. Verdolin LD, Borner AR, Mussi H, Gismondi RA, Schau $B$, Ramos RC. [Rhabdomyolysis associated with dengue fever in a lupic patient]. Rev Bras Reumatol. 2014; 54:318-21.

https://doi.org/10.1016/j.rbr.2013.02.003

PMID:25627228

55. Shanmugam S, Seetharaman M. Viral rhabdomyolysis. South Med J. 2008; 101:1271-72.

https://doi.org/10.1097/SMJ.0b013e318183649a

PMID:19005459

56. de Kanter CT, Keuter M, van der Lee MJ, Koopmans PP, Burger DM. Rhabdomyolysis in an HIV-infected patient with impaired renal function concomitantly treated with rosuvastatin and lopinavir/ritonavir. Antivir Ther. 2011; 16:435-37.

https://doi.org/10.3851/IMP1747

PMID:21555828

57. Warren-Gash C, Blackburn R, Whitaker H, McMenamin J, Hayward AC. Laboratory-confirmed respiratory infections as triggers for acute myocardial infarction and stroke: a self-controlled case series analysis of national linked datasets from Scotland. Eur Respir J. 2018; 51:1701794.

https://doi.org/10.1183/13993003.01794-2017 PMID:29563170

58. Umapathi $\mathrm{T}$, Kor AC, Venketasubramanian $\mathrm{N}$, Lim $\mathrm{CC}$, Pang BC, Yeo TT, Lee CC, Lim PL, Ponnudurai K, Chuah $\mathrm{KL}$, Tan PH, Tai DY, Ang SP. Large artery ischaemic stroke in severe acute respiratory syndrome (SARS). J Neurol. 2004; 251:1227-31.

https://doi.org/10.1007/s00415-004-0519-8 PMID:15503102

59. Bohmwald K, Gálvez NM, Ríos M, Kalergis AM. Neurologic alterations due to respiratory virus infections. Front Cell Neurosci. 2018; 12:386. https://doi.org/10.3389/fncel.2018.00386 PMID: 30416428

60. Moriguchi T, Harii N, Goto J, Harada D, Sugawara H, Takamino J, Ueno M, Sakata H, Kondo K, Myose N, Nakao A, Takeda $M$, Haro $H$, et al. A first case of meningitis/encephalitis associated with SARScoronavirus-2. Int J Infect Dis. 2020; 94:55-58.

https://doi.org/10.1016/j.ijid.2020.03.062 PMID:32251791

61. Zhao K, Huang J, Dai D, Feng Y, Liu L, Nie S. Acute myelitis after SARS-CoV-2 infection_ a case report. medRxiv preprint. 2020. https://doi.org/10.1101/2020.03.16.20035105

62. Burks JS, DeVald BL, Jankovsky LD, Gerdes JC. Two coronaviruses isolated from central nervous system 
tissue of two multiple sclerosis patients. Science. 1980; 209:933-34.

https://doi.org/10.1126/science. 7403860 PMID:7403860

63. Xu J, Zhong S, Liu J, Li L, Li Y, Wu X, Li Z, Deng P, Zhang J, Zhong N, Ding $Y$, Jiang $Y$. Detection of severe acute respiratory syndrome coronavirus in the brain: potential role of the chemokine mig in pathogenesis. Clin Infect Dis. 2005; 41:1089-96. https://doi.org/10.1086/444461 PMID:16163626

64. Chan JW, Bell KE. Global cerebral anoxia. Can J Neurol Sci. 2002; 29:88-90. https://doi.org/10.1017/s0317167100001797 PMID:11858543

65. Nathaniel TI, Williams-Hernandez A, Hunter AL, Liddy C, Peffley DM, Umesiri FE, Imeh-Nathaniel A. Tissue hypoxia during ischemic stroke: adaptive clues from hypoxia-tolerant animal models. Brain Res Bull. 2015; 114:1-12.

https://doi.org/10.1016/j.brainresbull.2015.02.006 PMID:25738761

66. Koehler U, Cassel W, Hildebrandt O, Kesper K, Kianinejad P, Nell C, Mayer G, Ohl G. [Obstructive sleep apnea in neurological diseases: specially as a risk factor for stroke]. Nervenarzt. 2014; 85:35-42.

https://doi.org/10.1007/s00115-013-3890-9 PMID:24362594

67. Losurdo A, Brunetti V, Broccolini A, Caliandro P, Frisullo G, Morosetti R, Pilato F, Profice P, Giannantoni NM, Sacchetti ML, Testani E, Vollono C, Della Marca G. Dysphagia and obstructive sleep apnea in acute, firstever, ischemic stroke. J Stroke Cerebrovasc Dis. 2018; 27:539-46.

https://doi.org/10.1016/j.jstrokecerebrovasdis.2017.0 9.051 PMID:29074066

68. Shereen MA, Khan S, Kazmi A, Bashir N, Siddique R. COVID-19 infection: origin, transmission, and characteristics of human coronaviruses. J Adv Res. 2020; 24:91-98.

https://doi.org/10.1016/j.jare.2020.03.005

PMID:32257431

69. Wang B, Li R, Lu Z, Huang Y. Does comorbidity increase the risk of patients with COVID-19: evidence from meta-analysis. Aging (Albany NY). 2020; 12:6049-57. https://doi.org/10.18632/aging.103000 PMID:32267833

70. Kuhn JH, Li W, Choe H, Farzan M. Angiotensinconverting enzyme 2: a functional receptor for SARS coronavirus. Cell Mol Life Sci. 2004; 61:2738-43. https://doi.org/10.1007/s00018-004-4242-5 PMID:15549175
71. Zhou $P$, Yang $X L$, Wang $X G$, Hu B, Zhang $L$, Zhang $W, S i$ $H R$, Zhu $Y$, Li B, Huang $C H$, Chen HD, Chen J, Luo $Y$, et al. Discovery of a novel coronavirus associated with the recent pneumonia outbreak in humans and its potential bat origin. bioRxiv. 2020.

https://doi.org/10.1101/2020.01.22.914952

72. Wang $Z, X u X$. scRNA-seq profiling of human testes reveals the presence of the ACE2 receptor, a target for SARS-CoV-2 infection in spermatogonia, leydig and sertoli cells. Cells. 2020; 9:920.

https://doi.org/10.3390/cells9040920

PMID:32283711

73. Tian Y, Rong L, Nian W, He Y. Review article: gastrointestinal features in COVID-19 and the possibility of faecal transmission. Aliment Pharmacol Ther. 2020; 51:843-51. https://doi.org/10.1111/apt.15731 PMID:32222988

74. Touyz RM, Li H, Delles C. ACE2 the janus-faced protein from cardiovascular protection to severe acute respiratory syndrome-coronavirus and COVID-19. Clin Sci (Lond). 2020; 134:747-50. https://doi.org/10.1042/CS20200363 PMID:32255491

75. Santos RA, Sampaio WO, Alzamora AC, Motta-Santos D, Alenina N, Bader M, Campagnole-Santos MJ. The ACE2/Angiotensin-(1-7)/MAS axis of the reninangiotensin system: focus on angiotensin-(1-7). Physiol Rev. 2018; 98:505-53.

https://doi.org/10.1152/physrev.00023.2016 PMID:29351514

76. Brodin P. Powerful populations respond to viruses and vaccines. Immunity. 2015; 43:1035-37. https://doi.org/10.1016/i.immuni.2015.11.018 PMID:26682979

77. Expert consensus on the prevention and control of novel coronavirus infections in neurology (first edition). 2020. http://www.cnstroke.com/

78. Brodin P, Davis MM. Human immune system variation. Nat Rev Immunol. 2017; 17:21-29. https://doi.org/10.1038/nri.2016.125 PMID:27916977

79. Guan WJ, Ni ZY, Hu Y, Liang WH, Ou CQ, He JX, Liu L, Shan H, Lei CL, Hui DS, Du B, Li LJ, Zeng G, et al. Clinical characteristics of 2019 novel coronavirus infection in China. medRxiv.

https://doi.org/10.1101/2020.02.06.20020974

80. Cecere TE, Todd SM, Leroith T. Regulatory T cells in arterivirus and coronavirus infections: do they protect against disease or enhance it? Viruses. 2012; 4:833-46. https://doi.org/10.3390/v4050833 PMID:22754651

81. Pérez CA. Looking ahead: The risk of neurologic complications due to COVID-19. Neurol Clin Pract. 2020: 10:371-74. 
https://doi.org/10.1212/CPJ.0000000000000836

82. Li G, Fan Y, Lai Y, Han T, Li Z, Zhou P, Pan P, Wang W, Hu D, Liu X, Zhang Q, Wu J. Coronavirus infections and immune responses. J Med Virol. 2020; 92:424-32. https://doi.org/10.1002/imv.25685 PMID:31981224

83. Racine $\mathrm{R}$, Winslow GM. IgM in microbial infections: taken for granted? Immunol Lett. 2009; 125:79-85. https://doi.org/10.1016/j.imlet.2009.06.003 PMID:19539648

84. Li Z, Yi Y, Luo $X$, Xiong $N$, Liu $Y$, Li S, Sun R, Wang $Y$, Hu $B$, Chen W, Zhang $Y$, Wang J, Huang $B$, et al. Development and clinical application of a rapid IgMIgG combined antibody test for SARS-CoV-2 infection diagnosis. J Med Virol. 2020; 10:1002. https://doi.org/10.1002/jmv.25727 PMID:32104917

85. Pneumonia Diagnosis and Treatment Program for Novel Coronavirus Infection (Trial Version 5). Chin J Integr Med. 2020.

86. Bloch EM, Shoham S, Casadevall A, Sachais BS, Shaz B, Winters JL, van Buskirk C, Grossman BJ, Joyner $M$, Henderson JP, Pekosz A, Lau B, Wesolowski A, et al. Deployment of convalescent plasma for the prevention and treatment of COVID-19. J Clin Invest. 2020; 130:2757-65. https://doi.org/10.1172/JCl138745 PMID:32254064

87. Sun T, Guan J. Novel coronavirus and the central nervous system. Eur J Neurol. 2020; 27:e52-e52.

https://doi.org/10.1111/ene.14227 PMID:32216009
88. Bleau C, Filliol A, Samson M, Lamontagne L. Brain Invasion by Mouse Hepatitis Virus Depends on Impairment of Tight Junctions and Beta Interferon Production in Brain Microvascular Endothelial Cells. J Virol. 2015; 89:9896-908.

https://doi.org/10.1128/JVI.01501-15 PMID:26202229

89. Corrales-Medina VF, Madjid M, Musher DM. Role of acute infection in triggering acute coronary syndromes. Lancet Infect Dis. 2010; 10:83-92. https://doi.org/10.1016/S1473-3099(09)70331-7 PMID:20113977

90. Li H, Cao B. New antiviral drugs for coronavirus are expected in 2019. 2020.

91. Arabi YM, Harthi A, Hussein J, Bouchama A, Johani S, Hajeer AH, Saeed BT, Wahbi A, Saedy A, AlDabbagh T, Okaili $R$, Sadat $M$, Balkhy $H$. Severe neurologic syndrome associated with Middle East respiratory syndrome corona virus (MERS-CoV). Infection. 2015; 43:495-501.

https://doi.org/10.1007/s15010-015-0720-y PMID:25600929 